Albert Sierra Reguera

\title{
Estudios de casos en mappings, 3D y realidad virtual en el patrimonio medieval Mappings, 3D and virtual reality in medieval heritage
}

Resumen: La introducción de las nuevas tecnologías en el sector del patrimonio en los últimos años ha abierto el camino a nuevas relaciones entre el público y los objetos patrimoniales. Tecnologías que hasta hace muy poco se utilizaban de forma puntual, como el escaneo 3D por ejemplo, son ahora utilizadas de forma generalizada y permiten a museos y gestores del patrimonio difundir su legado de formas insospechadas. La realidad virtual es otro de estos avances, y permite experiencias totalmente inmersivas, auténticos viajes en el tiempo donde el espectador se ve rodeado por el pasado. Los mappings, como ha sido el caso de \#Taüll1123, pueden conseguir también que la magia recorra las paredes de los monumentos donde se proyectan y explicar historias en imágenes. Todas estas herramientas, combinadas con la narrativa, y siguiendo siempre el rigor científico en la elaboración de los contenidos, son ejemplo de hasta donde podemos llegar en la difusión del patrimonio medieval.

Palabras clave: patrimonio; video-mapping; realidad virtual; fotogrametría; escáner.

Abstract: The emergence of new technologies in the heritage sector in recent years has opened the way for new relationships between the public and historical monuments and objects. Technologies that until recently were used for very specific needs, 3D scanning for example, are now used widely and allow museums and heritage managers to spread knowledge of their institutions and artefacts in unsuspected ways. Virtual reality is another of these advances, and allows completely immersive experiences, authentic journeys in time in which the viewer is surrounded by the past. Mappings, as in the case of \#Taüll1123, involve stories being told in projected pictures, the magic thus seen to be running across the very walls of monuments. All these tools, combined with a narrative, and always following academic rigor in the preparation of the content, are examples of how far we can go in the dissemination of historical knowledge within the context of medieval heritage.

Keywords: Heritage; Video-mapping; Virtual Reality; Photogrammetry; Scanner.

Albert Sierra Reguera, Responsable de Nuevas Tecnologías de la Agència Catalana del Patrimoni Cultural Generalitat de Catalunya

D Open Access. (c) 2019 Albert Sierra Reguera, published by De Gruyter. (c) BY-NC-ND This work is licensed under the Creative Commons Attribution-NonCommercial-NoDerivatives 4.0 License. https://doi.org/10.1515/9783110585421-016 


\section{Introducción: Las tecnologías y el patrimonio cultural en el siglo XXI}

Las nuevas tecnologías están transformando en las últimas décadas todos los ámbitos del saber y la creación, también el patrimonio cultural. Y han afectado a todos los vectores, sea la gestión como la conservación, o la comunicación con el público.

Desde el año 2000 hemos visto nacer en la gestión del patrimonio novedades como la venta online, el e-mail marketing (Crenshaw/Obermeyer 2003), los CRM (Pan 2015), o los inicios del tratamiento del Big Data (Stein/Wayman 2014). En conservación múltiples avances en el análisis de materiales (Gómez 2017), en la modelización $3 \mathrm{D}^{1}$ o la aparición de un nuevo sistema de iluminación, mucho más revolucionario de lo que aparenta, los LED (Vázquez-Moliní 2010). En la difusión, las redes sociales ya son ubicuas (La Magnética 2014), utilizamos apps y guías multimedia, hemos visto crecer el vídeo como soporte de comunicación masiva y podemos sumergirnos en entornos inmersivos como la realidad aumentada, la realidad virtual y los cada vez más frecuentes mappings.

Sin embargo, algunos de los proyectos tecnológicos más interesantes de los últimos años han combinado dos factores muy concretos: el objetivo de despertar en el público el placer del descubrimiento y la utilización de la narrativa como elemento clave de la estrategia comunicativa.

Cuando esto sucede, nos encontramos con proyectos que llegan a públicos que normalmente no están interesados por el patrimonio y que a través de estos nuevos caminos descubren su profundidad y diversidad. El mapping \#Taüll1123 (Íbar/Riu-Barrera 2014), las galerías de los diferentes museos europeos en la plataforma Sketchfab, ${ }^{2}$ las expediciones de realidad virtual de Google para escuelas... ${ }^{3}$ Son ejemplos de hasta donde se puede llegar en este momento en la creación de nuevas relaciones entre el público y el patrimonio.

\section{Las técnicas de creación de 3D en el patrimonio y su aplicación}

La creación de modelos 3D en el patrimonio es una técnica que se ha venido utilizando desde hace décadas, pero en la que, hasta hace bien poco, su complejidad

1 Smithsonian Digitization 3D, en línea, https://3d.si.edu/, consulta en 06/03/2018.

2 Sketchfab. Cultural Heritage, en línea, https://blog.sketchfab.com/category/community-story/ cultural-heritage/, consulta en 06/03/2018.

3 En línea, https://edu.google.com/expeditions, consulta en 06/03/2018. 
técnica y su elevado coste la convertían en un recurso a utilizar de forma puntual. En los últimos años, sin embargo, los avances en hardware y software como el desarrollo de nuevos escáneres de utilización mucho más sencilla, de precio razonable y utilizables en ordenadores convencionales, junto con la aparición de software de creación de modelos 3D a partir de fotogrametría, ha llevado a un punto en el que se está generalizando la utilización de estos modelos 3D en el sector del patrimonio. También ha colaborado a ello la aparición de mecanismos de difusión por Internet de estos modelos, como el programa profesional 3DHOP (Potenziani et al. 2014), o la plataforma Sketchfab (2017).

\subsection{Escaneado}

Existen dos sistemas de escaneado, a través de escáneres láser o a través de escáneres de patrones de luz blanca. Los primeros emiten un haz láser que impacta en múltiples puntos del objeto a escanear (Boardman/Bryan 2018). El escáner mide la distancia exacta a cada punto y a partir de este cálculo reconstruye la forma tridimensional del objeto. En arquitectura es especialmente útil porque permite, en muy poco tiempo, generar un modelo de una portada (Figura 15.1), una fachada o incluso de un edificio completo.

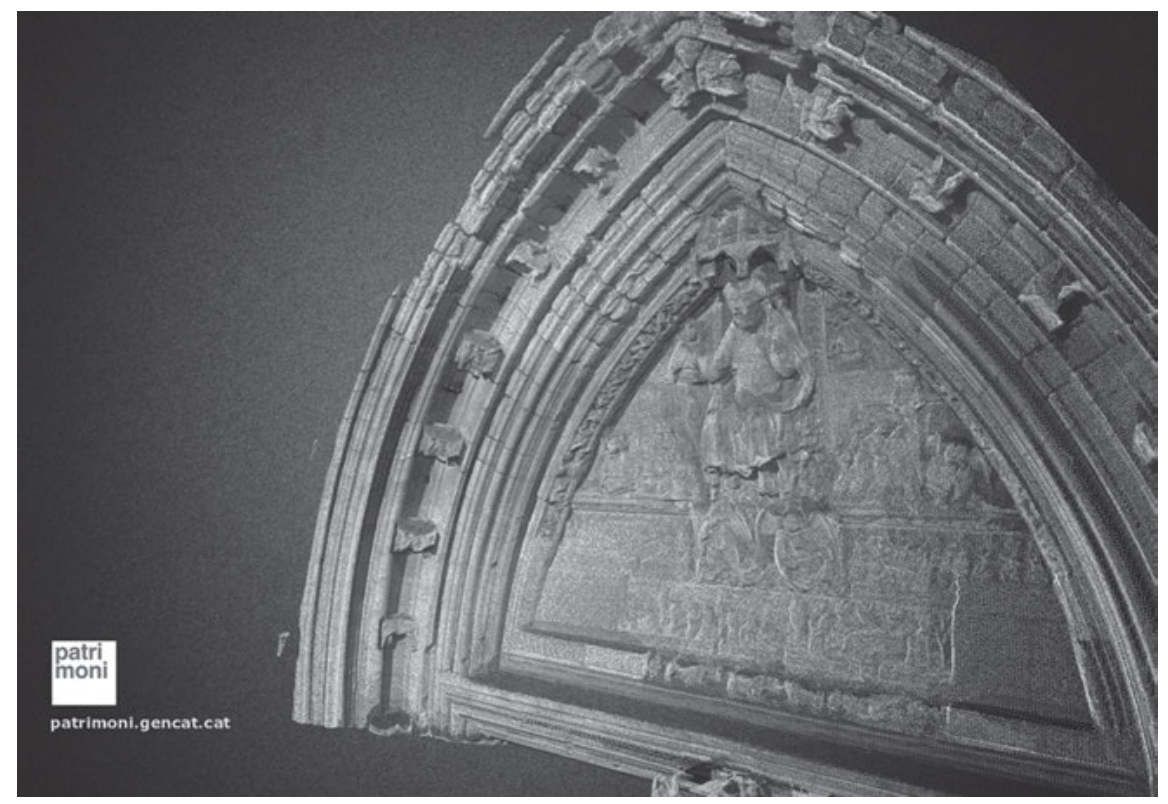

Figura 15.1: Modelo 3D de la portada de los Apóstoles de la Seu Vella de Lleida obtenido con escáner láser (Patrimoni.gencat). 
El segundo sistema de escaneado es el de luz blanca estructurada. En este caso el escáner proyecta con luz blanca diferentes patrones (líneas verticales, horizontales, diagonales) sobre el objeto a escanear y una cámara lee las deformaciones de estas líneas sobre la superficie irregular del objeto. A partir de esta información, calcula su forma tridimensional.

\subsection{Fotogrametría}

La fotogrametría se ha aplicado desde hace décadas en la cartografía para la creación de relieves. Requería, sin embargo, de personal especializado y de complejos visores estereoscópicos. Con la reciente aparición de software que permite la creación de fotogrametrías simplemente a partir de series de fotos y con un ordenador convencional (Photoscan, por ejemplo), este recurso ha pasado a ser utilizado en sectores muy diversos, uno de los cuales es el patrimonio (Bedford 2017). La metodología es muy sencilla, se toman series de fotos desde diferentes puntos de vista del objeto a modelar. El programa parte de puntos coincidentes de las fotografías para calcular desde que lugar exacto se han tomado y a partir de aquí recrear una nube de puntos que convenientemente densificada nos lleva a la forma del objeto (Figura 15.2).

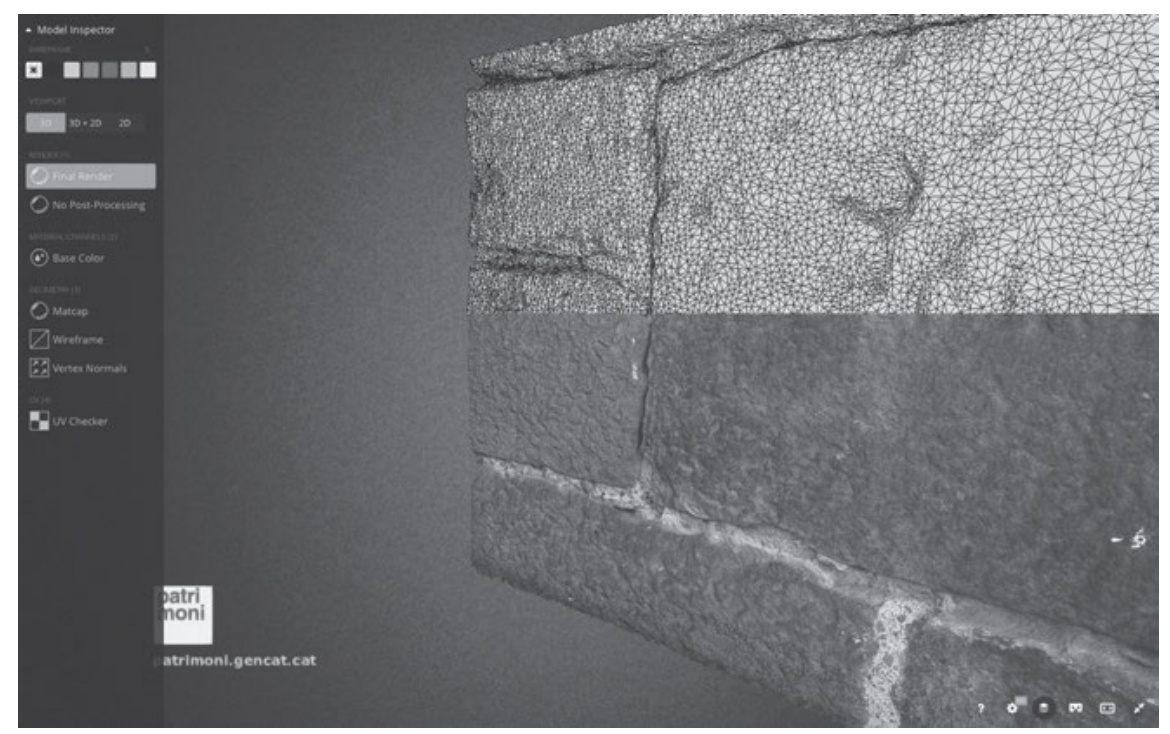

Figura 15.2: Modelo 3D de un sillar de Santa María del Mar, en Barcelona, obtenido por fotogrametría. En la parte superior la malla que forma su geometría. En la inferior, con la textura fotográfica aplicada (Patrimoni.gencat). 


\subsection{Modelado}

Un tercer método de construcción de modelos 3D es el modelado directo en programas de creación 3D como 3DS Max o Blender. Se puede utilizar para modelar objetos de los cuales se tiene información pero que han desaparecido, o sobre los que se quieren realizar modificaciones.

\subsection{Estudios de caso}

Como hemos comentado, uno de los potenciales objetivos de crear un modelo 3D es la oportunidad que brinda de crear una reproducción exacta a partir de este modelo. Es lo que se llevó a cabo en el caso del retablo de Cristo, obra de Bernat Saulet, un magnífico ejemplar gótico de piedra que se conserva en el Museu Episcopal de Vic. El museo acordó con la población de la que provenía el retablo realizar una copia que se instalaría en su lugar de origen, Sant Joan de les Abadesses. La captación se realizó con un escáner de luz blanca y la reproducción con una combinación de técnicas, una fresadora computerizada para todo el trabajo tridimensional, y posteriormente un acabado de las superficies manual hecho por escultores (Lozano Vilardell 2011-2012: 243-250).

Un ejemplo interesante de la evolución de los métodos de captación lo tenemos en la Portada del Monasterio de Santa María de Ripoll. En el año 1992 fue fotografiado por el Institut Cartogràfic de Catalunya que hizo una restitución fotogramétrica siguiendo la metodología cartográfica del centro. Podemos ver el resultado en el repositorio Calaix. ${ }^{4}$ En el año 2007 la UPC junto con el CNR.IT hicieron otro modelado, en este caso con escáneres Leica, cuyo resultado podemos ver en su web. ${ }^{5}$ Diez años después, con un simple móvil y el software Photoscan, el restaurador Aleix Barberà (2017) realizó una fotogrametría de prueba de uno de los fragmentos (Figura 15.3), y su calidad no desmerece en absoluto respecto a sus precedentes mucho más costosos. ${ }^{6}$

4 Portalada romànica de l'església del monestir de Ripoll, en línea, http://calaix.gencat.cat/ handle/10687/6972, consulta en 06/03/2018.

5 En línea, http://vcg.isti.cnr.it/europeana/portalada_ripoll/landing/portalada_ripoll.html, consulta en $06 / 03 / 2018$.

6 Portada de Ripoll (fragment) por Aleix Barberà, en línea, https://sketchfab.com/models/ 4147df790f9349b6a803c177b9a3311f, consulta en 06/03/2018. 


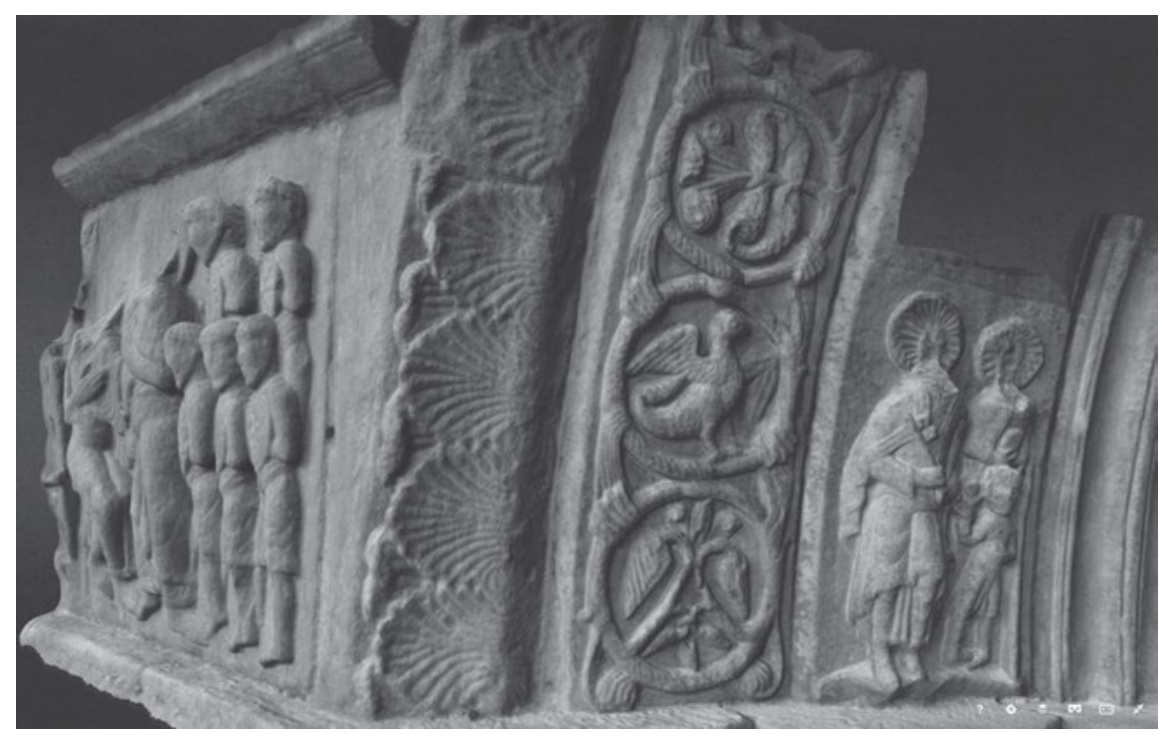

Figura 15.3: Modelo 3D de un fragmento de la portada de Ripoll (Aleix Barberà).

Quien quiera consultar modelos 3D de patrimonio medieval tiene un escaparate privilegiado en la plataforma Sketchfab. El visor que proporciona, de extraordinaria calidad, y el hecho de promover muy activamente la participación de entidades culturales en su seno, ha llevado a que sea en estos momentos la plataforma de difusión más interesante para los modelos 3D. Instituciones como el British Museum o el Museu d'Arqueologia de Catalunya tienen colecciones expuestas de extraordinaria calidad.

\section{La realidad virtual y la realidad aumentada}

\subsection{Realidad virtual}

La realidad virtual es una de las más interesantes revoluciones comunicativas que hemos vivido en los últimos tres años. Después de algunos proyectos experimentales en décadas anteriores con equipos complejos (Vote 2001; Pujol 2004), la utilización de la realidad virtual en el sector cultural se ve facilitada a partir del año 2015 con la aparición de los primeros dispositivos con distribución comercial y precios asequibles: Samsung Gear VR, Oculus Rift y HTC Vive (Figura 15.4). Algunos museos entendieron enseguida el potencial de este medio, ahora viable, 
e iniciaron experiencias piloto, como el Natural History Museum de Londres y sus experiencias de inmersiones submarinas con David Attenborough (Natural History Museum 2015).

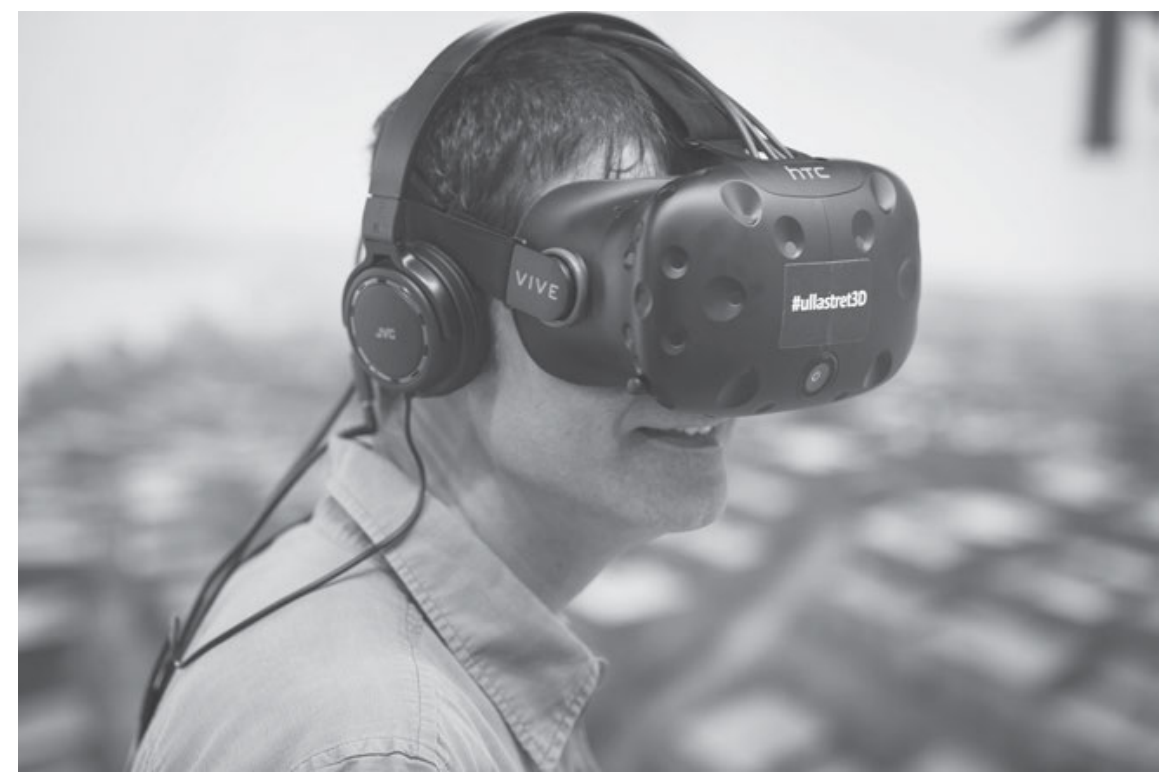

Figura 15.4: El dispositivo de realidad virtual HTC Vive (Patrimoni.gencat).

La realidad virtual, en su presentación más conocida en estos momentos (y dejando de lado otras posibilidades más experimentales) se basa en la utilización de un dispositivo con forma similar a unas gafas de bucear. En lugar de ser transparentes y mostrar el exterior, son opacas y disponen de dos lentes tras las que hay dos pantallas, una para cada ojo, que muestran un entorno virtual de forma estereoscópica. El dispositivo registra los movimientos de la cabeza del usuario y en cada momento le muestra la parte del mundo virtual correspondiente: si mira arriba, el cielo, si mira abajo, el suelo, y así sucesivamente. De esta manera se crea la ilusión de la inmersión en un mundo alternativo que se percibe como totalmente tridimensional.

Cualquiera que haya probado uno de estos dispositivos con contenido de calidad, se habrá dado cuenta de su inmenso potencial para la difusión cultural. No obstante, su implementación tiene una serie de dificultades que no es posible soslayar.

Por un lado, es un medio acabado de crear y con un lenguaje comunicativo que todavía está en sus albores. Los conceptos tradicionales del audiovisual, 
como el encuadre o el montaje, son inútiles en el nuevo medio, y la expresión se fundamenta en conceptos como la inmersión y la sensación de presencia (Pujol-Tost 2017). Los trabajos de Felix \& Paul para grandes marcas como el Cirque $d u$ Soleil o sobre todo los textos teóricos de Jessica Brillhart (2016) son los que en estos momentos están abriendo nuevos caminos.

Instalar equipamientos de realidad virtual en un museo puede ser muy atractivo, pero no es fácil. Es un medio que acaba de llegar y tiene un indudable efecto llamada, pero también problemas de falta de madurez (Forte et al. 2006). Para empezar, es un aparato que la mayoría del público no ha utilizado todavía y por lo tanto se hace necesaria una mínima instrucción por cada usuario. Son de uso individual y por tanto no son aptas para flujos importantes de visitantes. En el caso de los dispositivos móviles, aparte de los posibles problemas de seguridad, agotan la batería con rapidez por lo que deben estar conectados a la corriente. En el caso de los dispositivos más sofisticados como HTC o Oculus, requieren de un PC potente para cada estación y de un asiento autónomo y giratorio, o, aún mejor, de un espacio de $3 \times 3 \mathrm{~m}$ para que cada usuario pueda moverse por el espacio virtual.

Ante estas limitaciones hay diferentes posibilidades de utilización:

- Visita en grupo acompañados de un guía con un aparato móvil para cada persona.

- Instalación en una sala devarias estaciones $(10,20)$ con sesiones programadas.

- Alquilar estos equipamientos móviles en la entrada del museo para que el público los utilice durante su visita y los devuelva a la salida.

- Situar estaciones individuales a lo largo del recorrido de las salas del museo.

Hay otra dificultad más a afrontar, y esta es conceptual y comunicativa: el contenido y la gestión de la atención del visitante. En un yacimiento arqueológico la realidad virtual nos sirve para dar contexto a la realidad actual, para dar una visión que completa lo que vemos, y cada acción en la realidad virtual puede reforzar la densidad de contenidos y emociones de los restos reales. En un museo por contra, ¿cuando es realmente necesaria esta inmersión tan completa? Es una experiencia que para el visitante no es intrascendente. ¿Como la modulamos respecto al recorrido? No podemos pretender que el público entre y salga de una realidad a la otra a cada momento. Cada objeto cuenta una historia, cada vitrina proviene de un contexto. $\mathrm{O}$ elegimos un objeto o un conjunto concreto que merezca o necesite esta creación de contexto, o, si repartimos la atención en múltiples estímulos, acabaremos haciendo que el recurso esté trabajando en contra de los objetos, no a su favor.

El reto es este, experimentar con este nuevo medio y descubrir sus ventajas y como nos puede ayudar a crear nuevas conexiones y a llegar a estadios que anteriormente no éramos capaces de alcanzar. 


\subsection{Realidad aumentada}

Después de proyectos experimentales y enormemente interesantes como Archeoguide (Vlahakis et al. 2002), la aparición de dispositivos de distribución comercial (en este caso smartphones) a partir de 2009 llevaron a un período de utilización de la realidad aumentada (entre 2009 y 2013) que levantó muchas expectativas pero que pronto mostró también las limitaciones de la tecnología en ese estadio de desarrollo. Con la llegada de un juego muy elaborado, Pokemon Go, esta tecnología volvió a la palestra y con la creación de dos plataformas de programación por parte de Google y Apple (ARCore y ARKit, respectivamente) se han abierto de nuevo expectativas para su utilización en el sector cultural. La realidad aumentada recordemos que lo que nos ofrece es la presencia simulada de objetos virtuales integrados en la realidad que vemos a través de la pantalla de un móvil o tableta. A través de la tableta, utilizando su cámara, podemos ver, por ejemplo, la calle que estamos transitando, en la cual se integran objetos que no están en realidad presentes en ella, como, pongamos por caso, un mercado medieval. El nivel de calidad que permiten ahora ARCore y ARKit en la integración de realidad y objetos virtuales es impactante, pero pese a su potencial, hasta ahora no se han producido ejemplos en el sector cultural que hayan tenido un gran impacto.

\subsection{Realidad mixta}

El nuevo concepto de moda es la realidad mixta, en resumen, realidad aumentada en la que los objetos virtuales se presentan en el ambiente real, pero en este caso sin tabletas o teléfonos, sino con unas gafas especiales. Las Microsoft Hololens son el primer intento, bastante limitado y decepcionante, y todo el mundo espera durante el 2018 la aparición de las Magicleap, ${ }^{7}$ que según todas las pruebas efectuadas parece que llevarán este concepto a la realidad tangible.

\subsection{Estudios de caso}

¿Puede ser la realidad virtual una herramienta valiosa para el patrimonio cultural? Sin ningún genero de dudas lo es. Si pensamos específicamente en el patrimonio medieval, la RV es un medio que nos permite uno de los sueños de la humanidad, el viaje en el tiempo. Podemos recrear una ciudad, un mercado,

7 En línea, https://www.magicleap.com/, consulta en 06/03/2018. 
el entorno que se quiera, y en realidad virtual acceder a él y movernos por su interior sin limitaciones. Un ejemplo puede ser Historium, la atracción histórica del centro de Brujas, que ha publicado HistoriumVR, ${ }^{8}$ un paseo narrativo por los canales y plazas de la Brujas medieval (Figura 15.5).

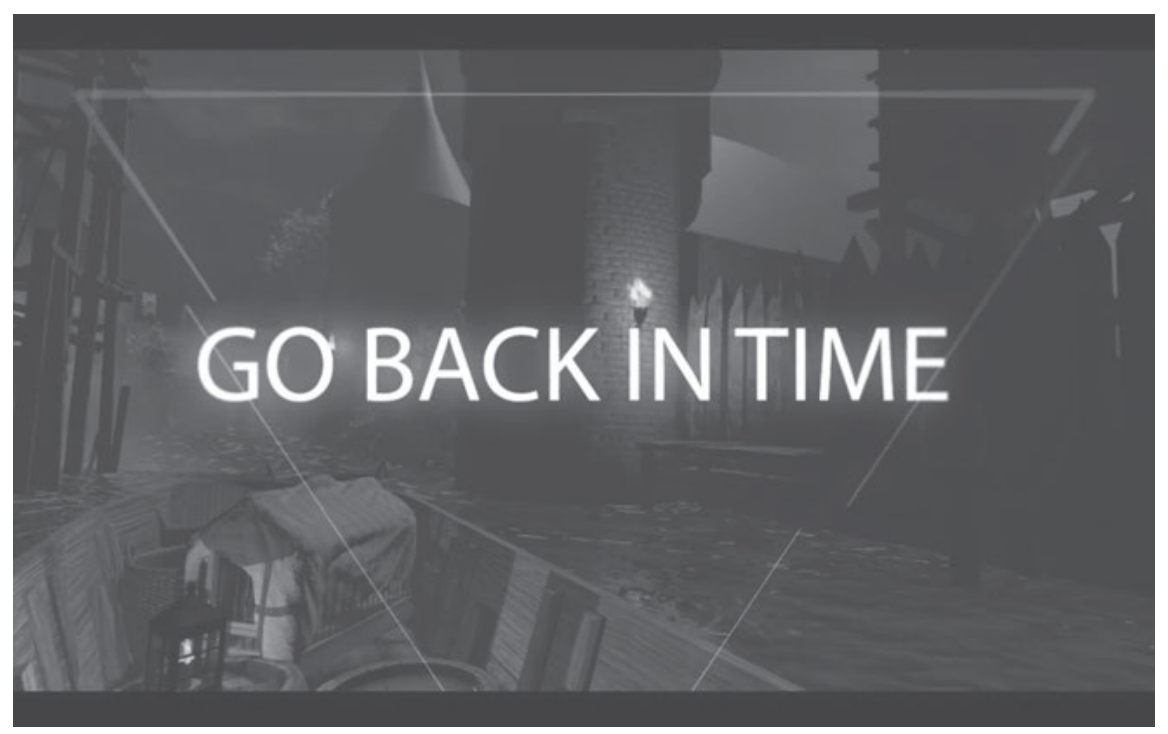

Figura 15.5: HistoriumVR (Historium).

Podemos viajar también en el espacio. Captar una imagen de 360 real y actual de un edificio medieval, como la Catedral de Colonia, por ejemplo, o mejor incluso, un modelado 3D de su interior y recorrerlo con las gafas de RV como nos propone Realities. ${ }^{9}$

En España probablemente el caso más interesante, a pesar de no ser medieval, es el de la reconstrucción virtual de la ciudad ibérica de Ullastret. ${ }^{10}$ A partir de la información científica obtenida en las últimas excavaciones, se realizó una reconstrucción completa de la ciudad y su entorno (Figura 15.6) que sirvió de base para la creación de una experiencia de realidad virtual en la que, de nuevo, la narrativa acompaña al visitante. En este caso, nos adentramos en el sueño de un

\footnotetext{
8 En línea, http://historiumvr.com/, consulta en 06/03/2018.

9 Cologne Cathedral St. Maternus Chapel, en línea, https://www.youtube.com/ watch?v=pIpCeE4PZB0, consulta en 06/03/2018.

10 Ullastret 3D, caminar por una ciudad ibérica de hace 2.000 años, en línea, http://patrimoni. gencat.cat/es/historias/ullastret-3d-caminar-por-una-ciudad-iberica-de-hace-2000-anos, consulta en 06/03/2018.
} 
antiguo jefe de la tribu de los indiketas que recuerda los hechos más relevantes de su juventud mientras recorre las calles vacías de la que fue su ciudad (Figura 15.7).

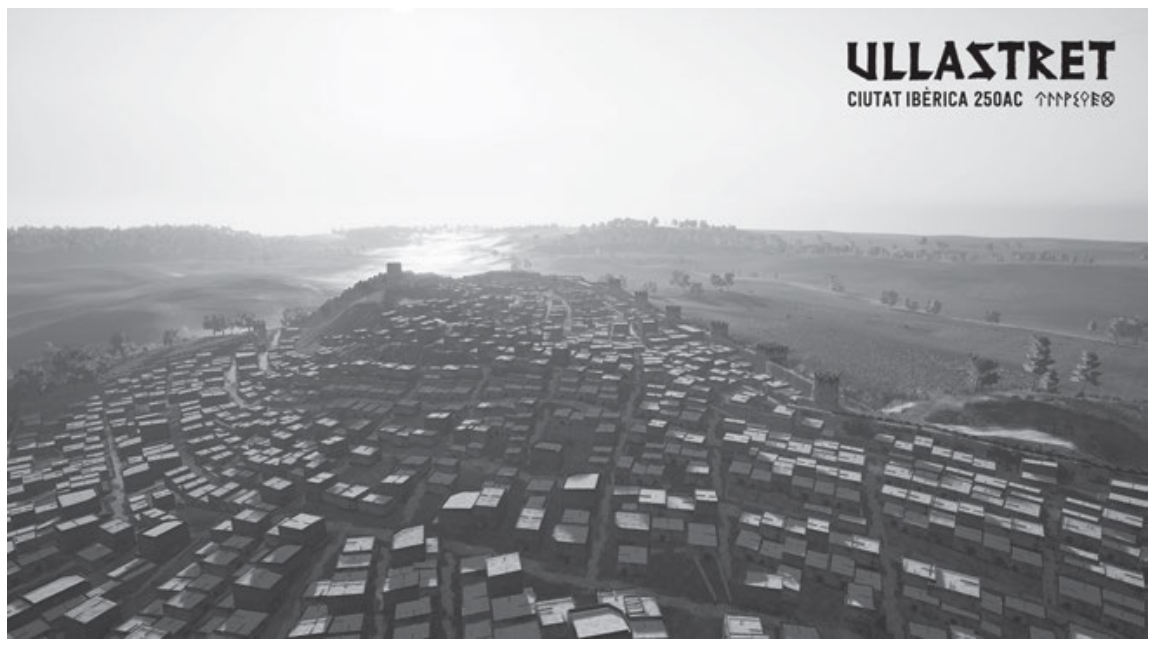

Figura 15.6: Reconstrucción virtual de la ciudad ibérica de Ullastret (Patrimoni.gencat).

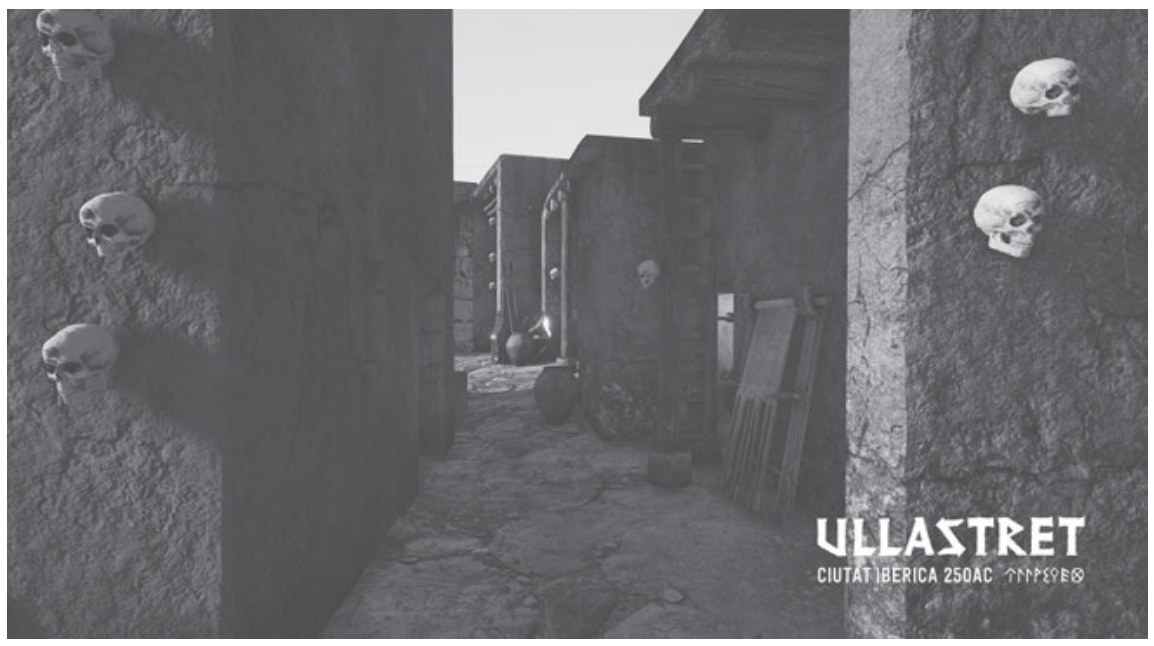

Figura 15.7: Una de las calles de Ullastret 3D (Patrimoni.gencat).

En el ámbito educativo, la iniciativa probablemente más difundida es la promovida por Google con sus “Expeditions” (2017), una app gratuita que puede ser utilizada por colegios de todo el mundo. A partir de la instalación en los smartphones de 
alumnos y profesor, y de la utilización de las gafas de realidad virtual más sencillas, las cardboard, el profesor guía a sus alumnos en diferentes recorridos en realidad virtual por paisajes y monumentos de todo el mundo.

\section{El mapping y su uso en museos y patrimonio arquitectónico}

\section{1 ¿Qué es el mapping?}

Conocido también como mapping audiovisual, video-mapping o projection mapping, consiste en la proyección sobre una superficie tridimensional (un edificio, un objeto simple o complejo) de una imagen en movimiento, adaptada a su superficie y ajustada a esta, de forma que simula que las acciones del vídeo ocurren realmente sobre ella. Las posibilidades son ilimitadas: desde proyecciones sencillas sobre un cubo en el que cada cara se convierte en una pequeña pantalla, a proyectar sobre la fachada de una catedral la simulación de su construcción desde los primeros bocetos, el levantamiento de los precarios andamios de madera y la recuperación de la policromía perdida.

\subsection{Antecedentes}

Un claro antecedente de los mappings podría ser identificado en el año 1952, cuando Paul Robert Houdin, conservador del castillo de Chambord puso en marcha el que muy probablemente fue el primer espectáculo audiovisual concebido para un edificio monumental, la recreación de una tormenta sobre el castillo (Boucher 1990; Lux 1956: 89; Lux 1956a: 114). El éxito fue tal que los Son et Lumière se extendieron por diferentes monumentos como Versalles, la Acrópolis de Atenas o diferentes lugares de América (McGrath 1992), pero probablemente el más conocido ha sido, desde su apertura en 1961, el de las pirámides de Giza que se ha perpetuado durante décadas (Marlowe 2001: 578-597).

\subsection{Aumentar la realidad}

En la visita cultural, a día de hoy, siempre hay algún grado de mediación entre el visitante y el objeto patrimonial. El museo, en sí mismo, es una máquina de 
crear significados a partir de los diferentes objetos que conforman su colección. Los medios que utiliza son diversos, desde la cartela al guía personal. La función última de estos medios es dirigir la mirada, explicar el contexto, o incluso revelar la maravilla que supone la creación artística.

En esta función de mediación entre la obra de arte y el público, en determinadas ocasiones un mapping puede ser una herramienta extraordinaria (Marlowe 2001); en realidad, si lo consideramos conceptualmente, es también una vía para crear realidad aumentada, porque puede ayudarnos a explicar una obra añadiendo nuevas capas de conocimiento a la realidad, o incluso, añadiendo visualmente capas de realidades alternativas a la realidad física, todo ello de forma transparente para el espectador, que se ve capturado por la magia que tiene ante sus ojos (Sierra 2015).

\subsection{La técnica del mapping}

El mapping, como hemos dicho, consiste en la proyección sobre una superficie tridimensional en la cual se simulan luces, sombras, colores o figuras en movimiento que toman apariencia de realidad. Para conseguir esto, generalmente el método es escanear el edificio o la superficie sobre la que se va a proyectar y crear un modelo 3D en un programa especializado. A partir de aquí, se añaden al modelo los efectos tridimensionales de iluminación o de proyección que se crean adecuados dentro de un programa de creación de mappings como puede ser MadMapper, Resolume u otros (Maniello 2015). Cuanto más ligado esté lo que se proyecta a la realidad física del elemento, más efectivo será: la lluvia deslizándose por los muros, hiedras subiendo por los balcones, personajes que entran y salen por las ventanas: todo esto será visto como una mágica ensoñación.

\subsection{El mapping en la escultura}

Una de las posibilidades del mapping, que ha venido siendo explorada fundamentalmente por los museos, es la de crear mappings sobre esculturas. Ejemplos como Golem x MBA, en el Museo de Bellas Artes de Lyon, en el cual, por unas jornadas, algunas esculturas cobran vida, se proyectan sobre ellas ojos que se abren (Figura 15.8) o rostros que sufren ante la mirada de los espectadores; ${ }^{11}$ o la

11 BK-France, en línea http://www.bk-france.com/\#/golemxmba/, consulta en 06/03/2018. Golem-x-MBA, en línea, https://www.behance.net/gallery/27036259/Golem-x-MBA, consulta en 06/03/2018. 
Williamson Art Gallery and Museum con su proyecto Starkers de los artistas Davy y Kristin McGuire, en el que una escultura femenina desnuda nos desvela los prejuicios implícitos de cada espectador. ${ }^{12}$

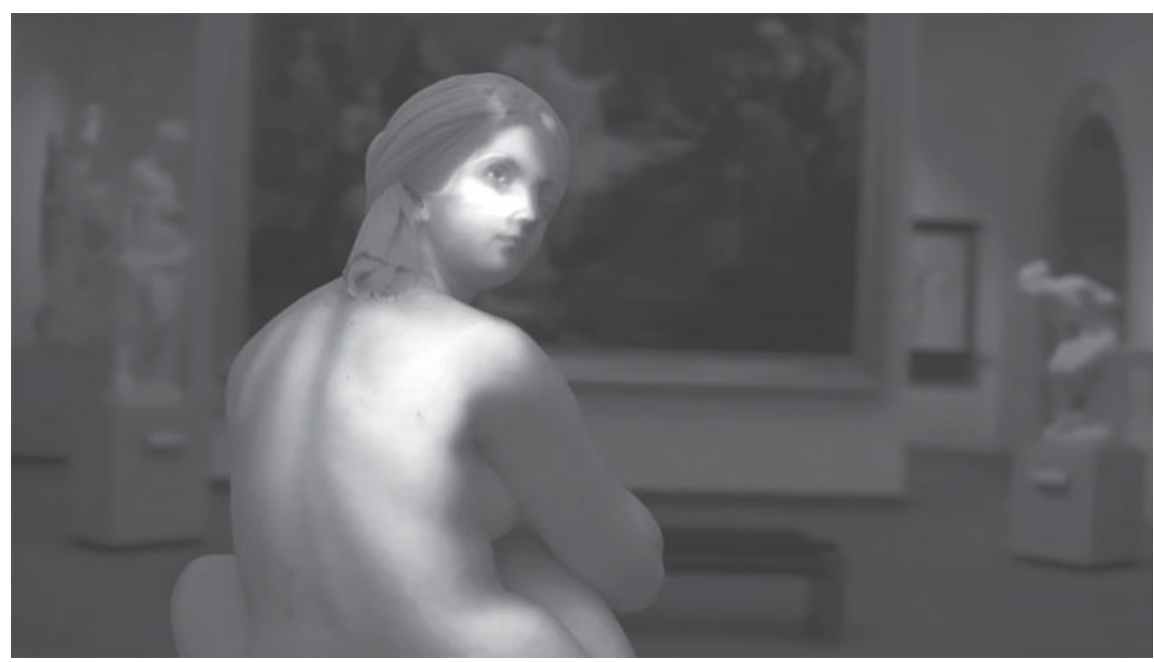

Figura 15.8: Golem x MBA (BK Digital Art Company).

\subsection{El mapping en la arquitectura}

Si los son et lumière son indudablemente franceses, no debería extrañarnos que desde hace décadas en Francia se haya experimentado con este tipo de proyecciones. La empresa Skertzò (actualmente Athem-Skertzò) comenzó en 1999 en la catedral de Amiens devolviendo la policromía a las figuras de la fachada en sesiones nocturnas, con un tremendo éxito. ${ }^{13}$ Desde los primeros proyectores de imágenes fijas, la evolución tecnológica ha llevado estas proyecciones sobre catedrales y castillos hasta sofisticadas creaciones 3D en las que vemos infinidad de efectos, como en los ejemplos de Reims, Rouen, Poitiers o Strasbourg (Figura 15.9): el trazado de los planos, el levantado de andamios, los perfiles de

12 Starkers, en línea http://www.davyandkristinmcguire.com/starkers.html, consulta en 06/03/2018.

13 La colorisation de la cathédrale d’Amiens (2008), en línea, http://fresques.ina.fr/picardie/fichemedia/Picard00719/la-colorisation-de-la-cathedrale-d-amiens.html, consulta en 06/03/2018. 
los obreros trabajando en ellos, las piezas de la catedral montándose como si de un puzzle se tratara, la luz de las vidrieras, los detalles de la escultura... ${ }^{14}$

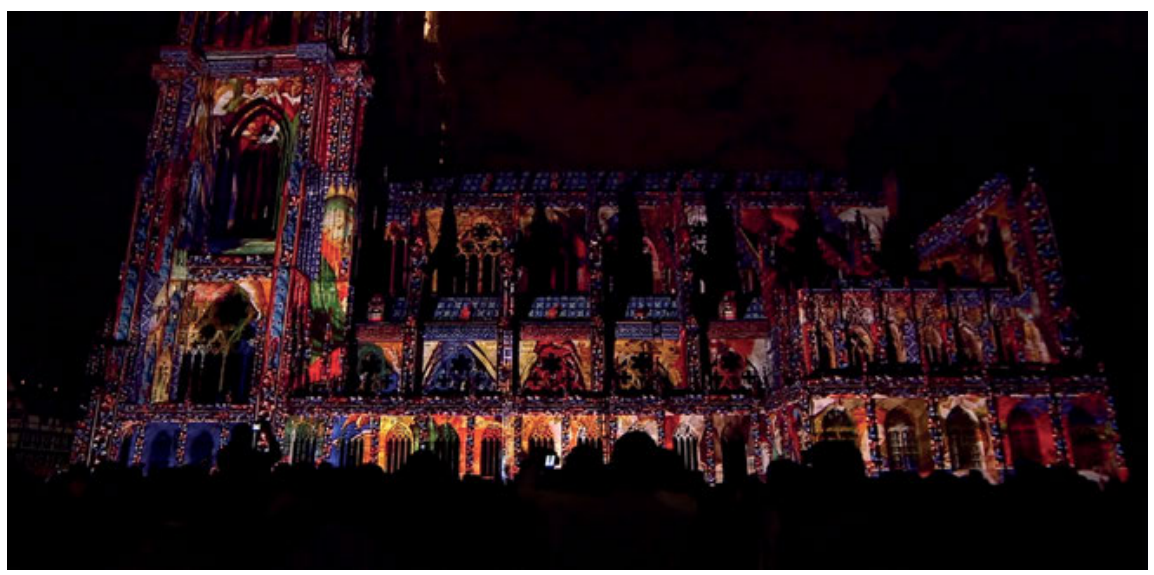

Figura 15.9: Mapping de la catedral de Strasbourg (Athem-Skertzò).

Pero si un proyecto destacó en su momento por la creatividad y por su integración entre la historia y creación visual, fue el dedicado al 600 aniversario del Reloj Astronómico de Praga en el año 2010. La profunda comprensión de los valores del monumento y su transmisión a un guión audiovisual lleno de imaginación lo han convertido en un referente. ${ }^{15}$ Todo gira, como es lógico, alrededor del concepto del tiempo, incluso los efectos lumínicos; la representación de los astros sobre la esfera del reloj, los muros que se abren para mostrar los mecanismos de relojería, todo es un derroche de creatividad y buen gusto.

\subsection{Video-instalaciones complejas}

En la frontera del video-mapping están las video-instalaciones a partir de imágenes culturales en grandes pantallas que configuran una sala o un espacio complejo. Probablemente el más conocido, es Van Gogh Alive donde imágenes de los cuadros del pintor son proyectadas sobre diferentes superficies de forma

14 Athem-Skertzò, en línea, https://www.athem-skertzo.com/, consulta en 06/03/2018. 15 En línea, https://vimeo.com/130039339, consulta en 06/03/2018. 
que envuelven totalmente al espectador. ${ }^{16}$ Pero si nos atenemos a lo medieval, el mismo concepto es el que recientemente puso en marcha el Museo del Prado con motivo de su exposición dedicada al Bosco, con la instalación el Jardín Infinito (Figura 15.10), creada por los artistas Álvaro Perdices y Andrés Sanz. ${ }^{17}$ Múltiples proyectores dan forma a un recorrido que se convierte en un laberinto por el interior del Jardín de las Delicias donde el espectador se ve totalmente inmerso en el universo del pintor flamenco.

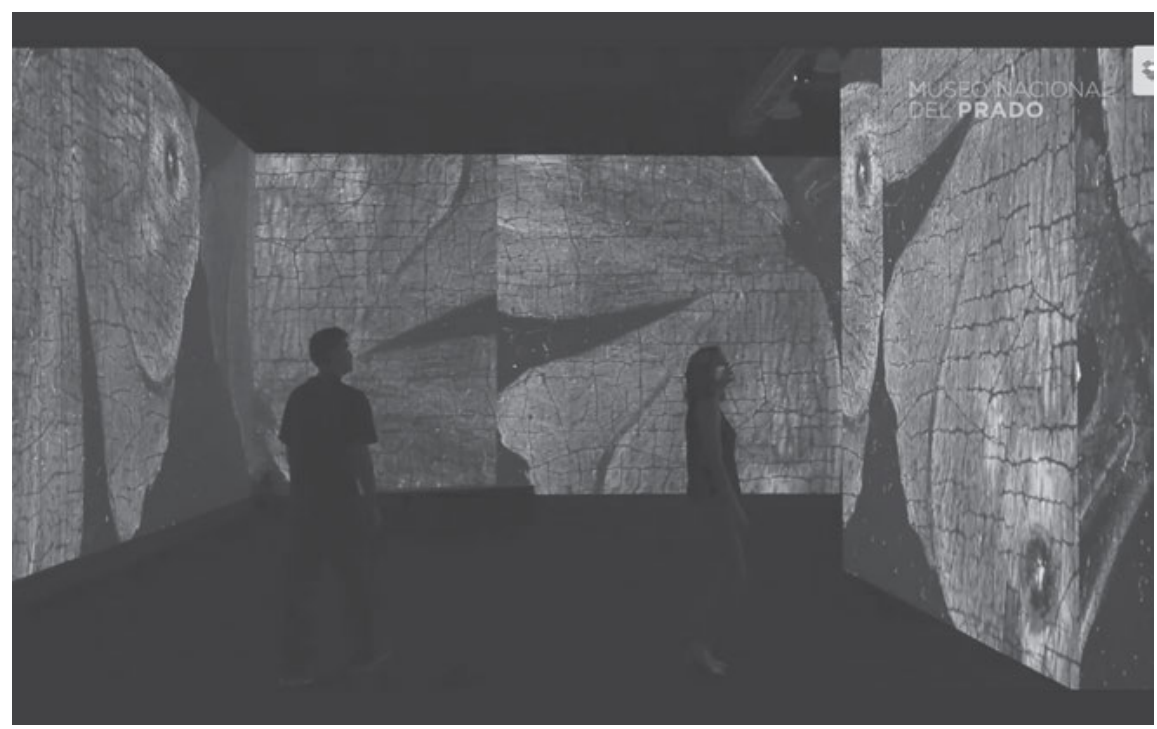

Figura 15.10: El Jardin Infinito (Museo del Prado).

\section{5 \#Taüll1123. Una experiencia de mapping en una iglesia patrimonio mundial}

Hemos visto hasta ahora una breve panorámica de las diferentes tipologías existentes de mapping sobre elementos culturales y patrimoniales. Ahora nos centraremos en un ejemplo concreto de comunicación del patrimonio medieval, el

16 En línea, http://grandeexhibitions.com/van-gogh-alive-the-experience/, consulta en 06/03/2018. 17 En línea, https://www.museodelprado.es/actualidad/exposicion/jardin-infinito/8776099bf37a-4c5e-b706-e8b06928a4ae, consulta en 06/03/2018. 
proyecto \#Taüll1123 en el que, a partir de la necesidad de generar una nueva copia de las pinturas para instalarla en el ábside la iglesia, se desarrolló un proyecto de mapping audiovisual que ha sido unánimemente reconocido (Mateos/Guifreu 2014: 527-533) como el Laus de Oro o el Premio al Mejor multimedia de 2014 en el congreso internacional Museums and the Web en Baltimore.

\subsection{Sant Climent de Taüll}

De entre las iglesias del Valle de Boí, Sant Climent de Taüll es sin lugar a dudas la más conocida, gracias principalmente a sus pinturas murales, y en especial por el Cristo en Majestad, que después de complejas vicisitudes fue trasladado al Museo de Arte en Barcelona, actual Museu Nacional d'Art de Catalunya. El conjunto de iglesias del valle fue objeto de protección legal a partir de 1992 y de una larga serie de intervenciones de restauración (Abelló/Sierra 2000) y finalmente declarado como Patrimonio Mundial por la Unesco en el año 2000.

En 2012, el estado de la iglesia requería de una intervención urgente: en la cubierta y en los ábsides aparecían humedades, la museografía del año 2000 había quedado anticuada, el pavimento del ábside necesitaba de un nuevo acabado después de una intervención arqueológica y finalmente la copia de las pinturas del ábside realizada en el año 1959 estaba en muy mal estado.

\subsection{La propuesta de restauración}

A partir de esta situación, se fue configurando una propuesta de restauración ${ }^{18}$ para solucionar las deficiencias detectadas, pero que por encima de todo devolviera el esplendor a la iglesia, dotándola de una mejor calidad de visita y potenciando los valores arquitectónicos y pictóricos que atesoraba y que en ese momento estaban enmascarados. Cabe destacar en este sentido que en los muros del templo resta

18 La restauración formaba parte del programa Románico Abierto promovido por el Departament de Cultura de la Generalitat y la Obra Social "La Caixa”. En la intervención de Sant Climent de Taüll se contó con la colaboración del Museu Nacional d’Art de Catalunya, del Obispado de Urgell y del Consorcio del Patrimonio Mundial de Vall de Boí. Existen diferentes artículos sobre esta actuación (Riu-Barrera/Tarrida 2014; Íbar/Riu-Barrera 2014; Camps/Sierra 2015; Sierra 2015; Sierra 2017: 82-100), de la que también se puede obtener información y recursos audiovisuales en la web http://pantocrator.cat/ (consulta en 06/03/2018) y en el canal de YouTube de Románico Abierto en la lista de reproducción dedicada a \#Taüll1123 (https://www.youtube.com/ playlist?list=PLR_E_85NaaaFxRk71S2dYu4vVHurbplNW, consulta en 06/03/2018). 
gran cantidad de pintura mural románica, como por ejemplo la figura de un can entre cenefas sobre el ábside del evangelio, las figuras de San Clemente y San Pedro en los pilares, o la escena de Caín y Abel en el presbiterio (Pagès 2013: 151-172).

La primera propuesta fue la de crear una nueva copia física, pero quedó rápidamente descartada cuando en el proceso de estudio documental se detectó una fotografía en la cual se veía claramente como tras el arrancado de las pinturas del ábside, restaban en el muro trazos más que visibles de las capas profundas de la pintura original. Para confirmar esta hipótesis se realizaron catas y endoscopias que confirmaron su existencia.

\subsection{La reproducción virtual proyectada}

A partir de este momento, se busca la manera de recuperar esta pintura mural existente y compatibilizarla con la presentación de la pintura desaparecida. La vía investigada fue la de la reproducción virtual proyectada, que presentaba una gran virtud: permitir una recuperación total de la originalidad matérica en los muros y, simultáneamente, ofrecer una visión de las pinturas trasladadas al museo, dos objetivos que con la copia física eran excluyentes. De esta forma la recuperación del potencial cultural del templo era máximo.

La proyección abría además un nuevo camino, la posibilidad de crear un fragmento audiovisual que conectara con el público tanto a través del intelecto como a través de su empatía y emociones. Hacerle conocer las pinturas más en profundidad, pero también ayudarle a apreciarlas con detalle y a sentirlas como parte de un legado común.

Se realizaron diferentes ensayos para comprobar si los niveles de calidad de la proyección sobre la superficie del ábside eran adecuados, y si se estaba dentro de los límites lumínicos aconsejados por la conservación de las pinturas. Los ensayos fueron enormemente positivos y se pasó a formar el equipo multidisciplinar que llevaría a cabo el proyecto, Burzon`Comenge en la parte gráfica y Playmodes en la parte tecnológica.

Tratándose de una iglesia declarada Patrimonio Mundial por la Unesco, la exigencia de calidad técnica y artística era máxima. La proyección en sí misma era muy compleja, porque la superficie concernida (el ábside, el presbiterio, el frontis superior) combinaba superficies planas con cóncavas y además con fragmentos existentes, con los que la proyección debía encajar al milímetro. Toda la operativa tecnológica (proyectores, ordenadores, cableado) tenía que ser prácticamente invisible para el espectador, con el objetivo de mantener la idiosincrasia del lugar y la calidad de visita. El mapping no era un espectáculo, sino un elemento más de la visita, consustancial a la arquitectura y en continuidad con esta y con la lectura cultural del conjunto. 


\subsection{La intervención}

Así pues, se programó una intervención unitaria que constaba de cuatro operaciones principales: el estudio científico del edificio y las pinturas, la restauración arquitectónica, que incluía medidas de conservación y de mejora de la visita, la restauración pictórica y finalmente la instalación de la copia virtual por proyección, el mapping.

Se inició con el estudio de la documentación escrita y fotográfica que existe sobre Sant Climent de Taüll, y la inspección detallada de las pinturas existentes en los muros de la iglesia, así como la de las conservadas en el Museu Nacional d'Art de Catalunya con objeto de preparar las imágenes que servirían de base al mapping.

En la intervención arquitectónica se construyó un drenaje perimetral y se repararon las cubiertas para evitar las humedades, se diseñó un nuevo pavimento del presbiterio de madera y un nuevo altar en su centro que recuperaba el ara original. Se renovaron las instalaciones de la iglesia, con una nueva iluminación interior que resaltaba los fragmentos de pintura existentes y también una nueva museografía con paneles de señalización, vitrinas que albergan las esculturas románicas del templo y dos módulos audiovisuales.

La operación más importante previa a la instalación del mapping fue indudablemente la restauración de las capas profundas originales del ábside. Para ello se retiró la copia del año 1959 bajo la que apareció una capa de pintura (azulete) que cubría por completo las pinturas originales. A punta de espátula y bisturí (Figura 15.11), se fue retirando esta capa superficial y tras cuatro meses de trabajo las capas pictóricas originales estaban ya a la vista.

En paralelo a los trabajos de conservación, se comenzó el desarrollo de la copia virtual y el mapping, que se planeó con tres estadios (Figura 15.12). El primero, la realidad matérica: las capas profundas y las pinturas conservadas realmente en los muros. El segundo, la copia virtual propiamente dicha, que superponía a las capas profundas las pinturas existentes en el MNAC y las hacía coincidir con los fragmentos todavía existentes en los muros. En este segundo estadio el visitante contemplaba la realidad matérica y la realidad virtual imbricadas, como si las pinturas hubieran vuelto a su lugar de origen. Y finalmente el tercer estadio era la presentación de una hipótesis de cómo eran las pinturas en 1123, justo en el momento de su creación. Se optó por darle un carácter narrativo, porque de esta manera se subrayaba su condición de hipótesis, pero también porque permitía abordar los aspectos que se querían comunicar: el propio hecho pictórico, mostrando el proceso de creación; la calidad artística y formal, recreando la pincelada en los fragmentos más relevantes, la iconografía y los significados, a partir de la individualización de personajes. Todo ello sin palabras, con el objetivo de hacer ver, de 


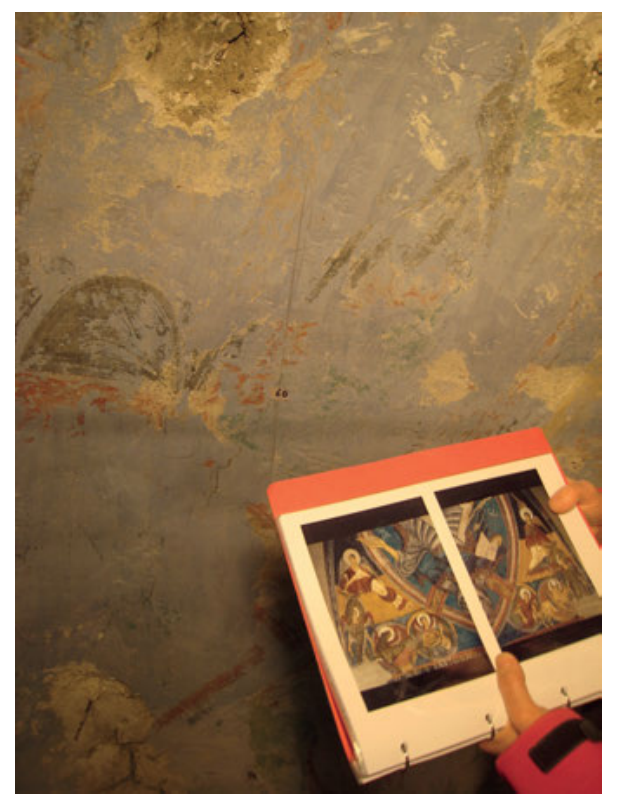

Figura 15.11: Recuperación de las capas profundas de la pintura original románica en el ábside de Taüll.

(Servei del Patrimoni Arquitectònic. Generalitat de Catalunya).

transformar la mirada del visitante, grabando en su memoria visual las imágenes de la pintura para que después, cuando desaparezca la virtualidad, las reconozca en los restos físicos.

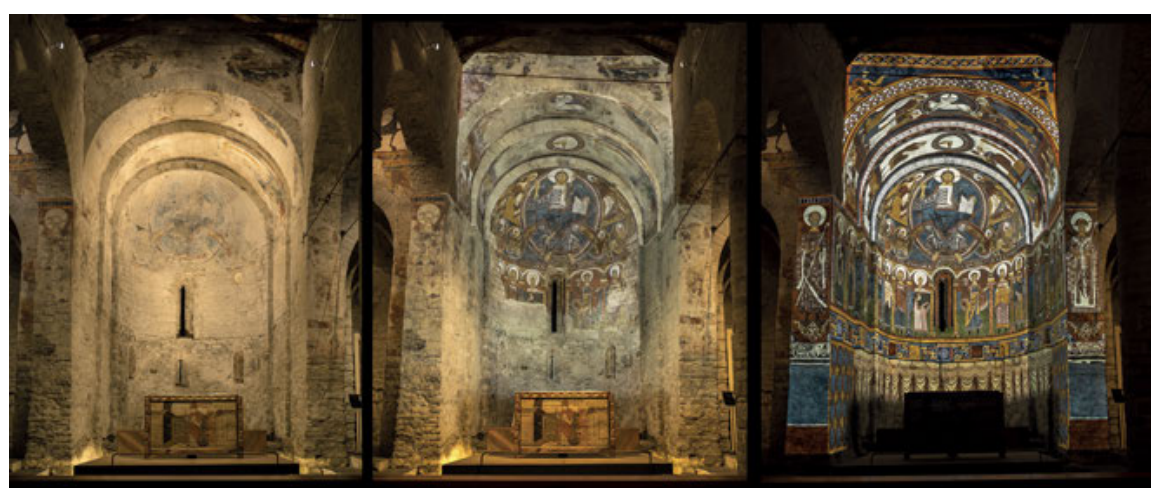

Figura 15.12: Los tres estadios de \#Taüll1123 (Eloi Maduell/Patrimoni.gencat). 


\subsection{La solución tecnológica}

Técnicamente, para conseguir la copia virtual se elaboró una réplica exacta de la volumetría en 3D del presbiterio con un escaneado láser de la iglesia en la que se insertaron las imágenes digitales de alta resolución de las pinturas (Figura 15.13).

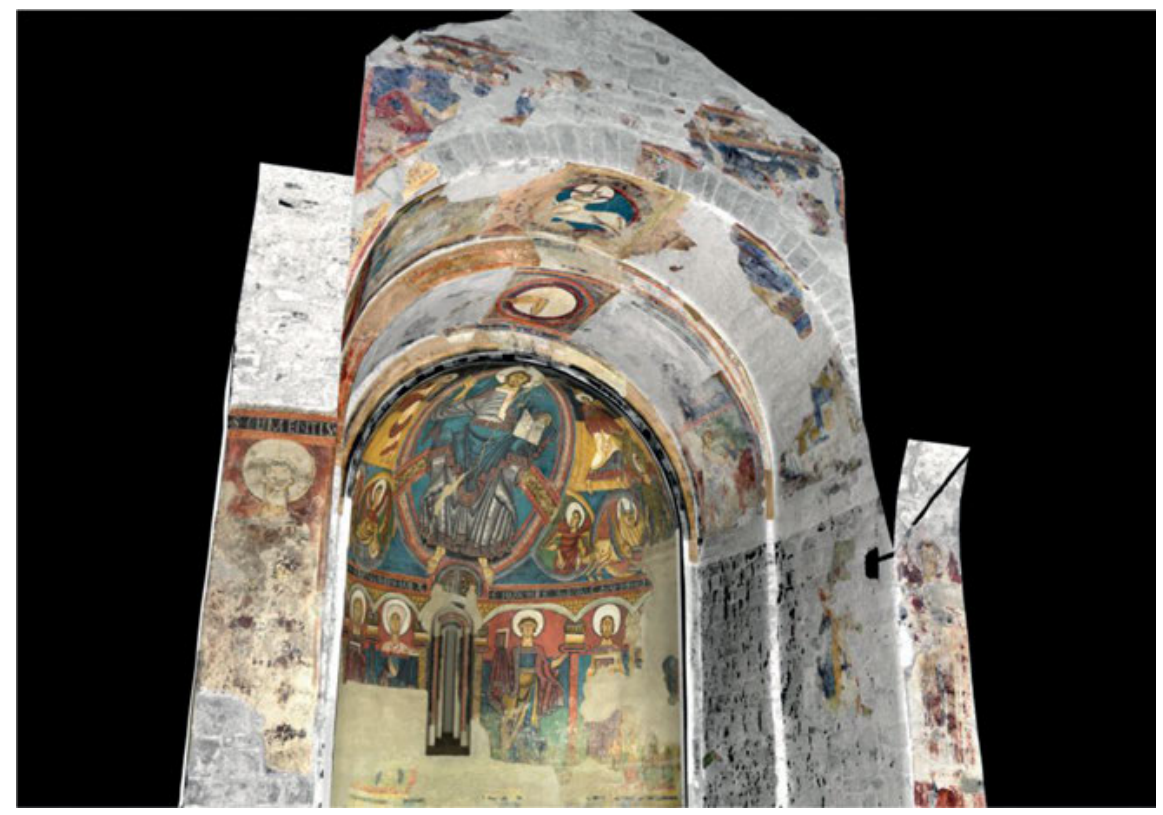

Figura 15.13: El modelado 3D del ábside de Taüll (Calidos).

De esta forma se conseguía ya el material para los dos primeros estadios de proyección, pero, para construir el tercero, era necesaria la restauración virtual de las pinturas y su “deconstrucción” - por así decirlo- en sus diferentes capas, para poder posteriormente animarlas. Se retocaron grietas y lagunas del original, marcas de corte y otras irregularidades. Se recuperaron colores y perfiles de las partes degradadas a partir del estudio y la comparación con los fragmentos mejor conservados. Y finalmente, para la recreación de las partes perdidas de la pintura, se siguió la organización en registros con ritmos y medidas precisas de esta pintura románica, afrontando así esta reconstrucción sobre bases sólidas. El estudio de la geometría general, de las cenefas, colores de fondo, elementos arquitectónicos y decorativos y los pequeños fragmentos existentes en algunas escenas han permitido una reconstrucción detallada con algunas figuras delineadas por primera vez (Figura 15.14). 


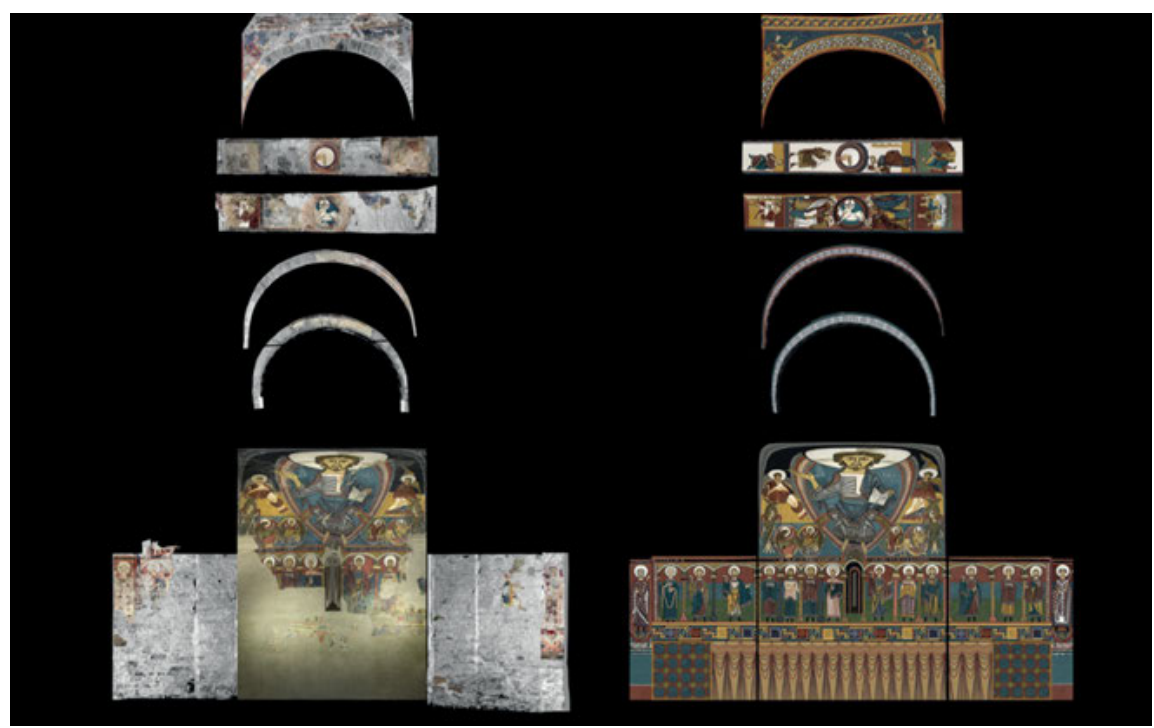

Figura 15.14: La restitución hipotética de las pinturas murales románicas de Sant Climent de Taüll (Burzon*Comenge).

Por lo que respecta al sistema de proyección, la especial geometría de la superficie a bañar de imágenes obligó a un esquema complejo de seis proyectores (Figura 15.15): dos situados sobre el módulo de acceso a la iglesia que cubrían el frontis del presbiterio y el muro central del ábside, dos más en las naves laterales para cubrir en ángulo los muros laterales del presbiterio. Finalmente, los dos últimos se ubicaron en el ábside ocultos tras el banco presbiterial y proyectaban las imágenes del intradós de los arcos presbiteriales y a la bóveda del ábside.

El control de proyección se planificó que tuviera lugar desde dos ordenadores situados también sobre el módulo de entrada (uno máster y el otro esclavo) con el programa Wings de Vioso, que enviaban la señal a cada proyector, realizando el encaje con cada sector de los muros y controlando también la iluminación de la iglesia, a través de protocolo DMX. El control de puesta en marcha, que puede ser automático o manual, se hacía desde el control de entrada.

Los proyectores utilizados fueron los Christie 550-G y 675-E con ópticas que van desde el gran angular $(0,85)$ al teleobjetivo $(4.0)$ en función de la zona a cubrir. $^{19}$

19 Christie en la proyección virtual de las pinturas originales de Sant Climent de Taüll, en línea, https://www.christiedigital.com/emea/business/visual-solutions-case-studies/visual-solutionsapplication-stories/sant-climent-de-taull-spanish, consulta en 06/03/2018. 


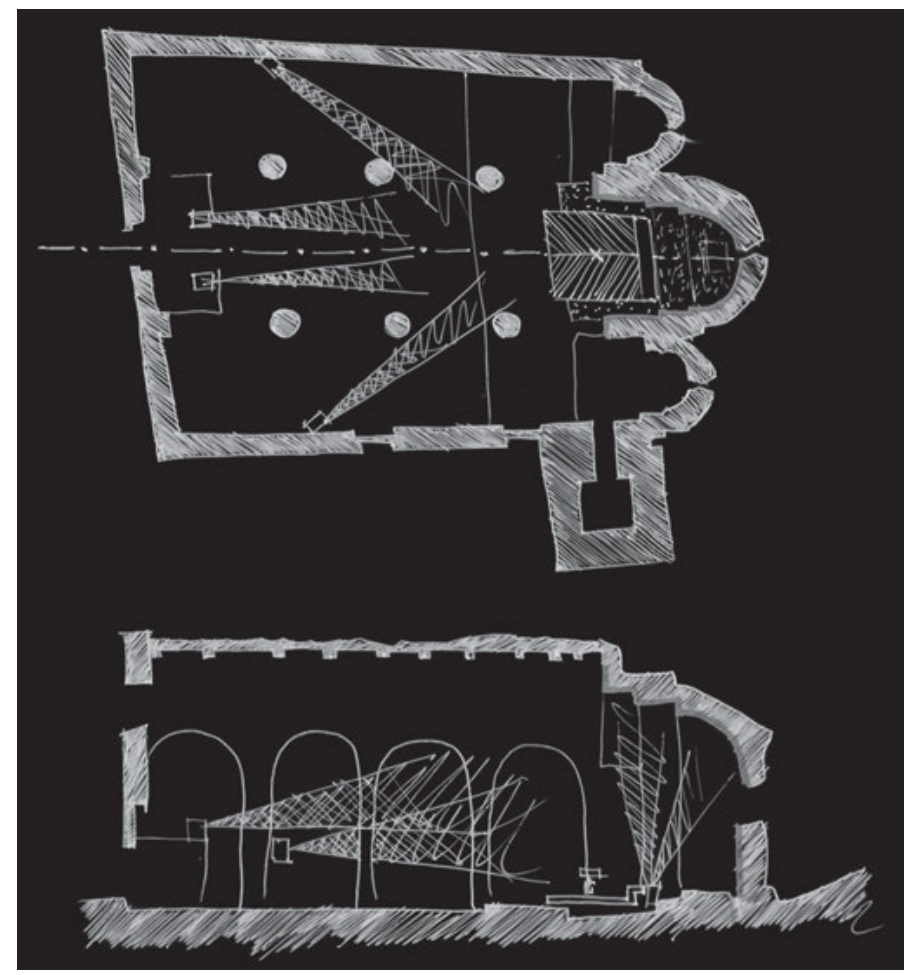

Figura 15.15: Esquema de proyección de \#Taüll1123 (Burzon*Comenge).

Con esta disposición, la instalación tecnológica era prácticamente invisible para el espectador, y el detalle conseguido en cada una de las secciones era muy bueno, sin problemas de pixelado aparente.

\subsection{La presentación al público}

El objetivo inicial, que la proyección no apareciera como tal, sino que se integrara en la superficie real de los muros de forma transparente, fue conseguido, y en el segundo estadio, las pinturas físicas y proyectadas conviven visualmente de forma armoniosa (Figura 15.16).

La banda sonora, creada especialmente para la ocasión, se trabajó con los mismos criterios que la parte visual, una combinación de recuperación científica y creatividad contemporánea. Se grabaron, por un lado, los sonidos de ambiente en la propia iglesia y en el valle y, por otro, diferentes instrumentos medievales, 


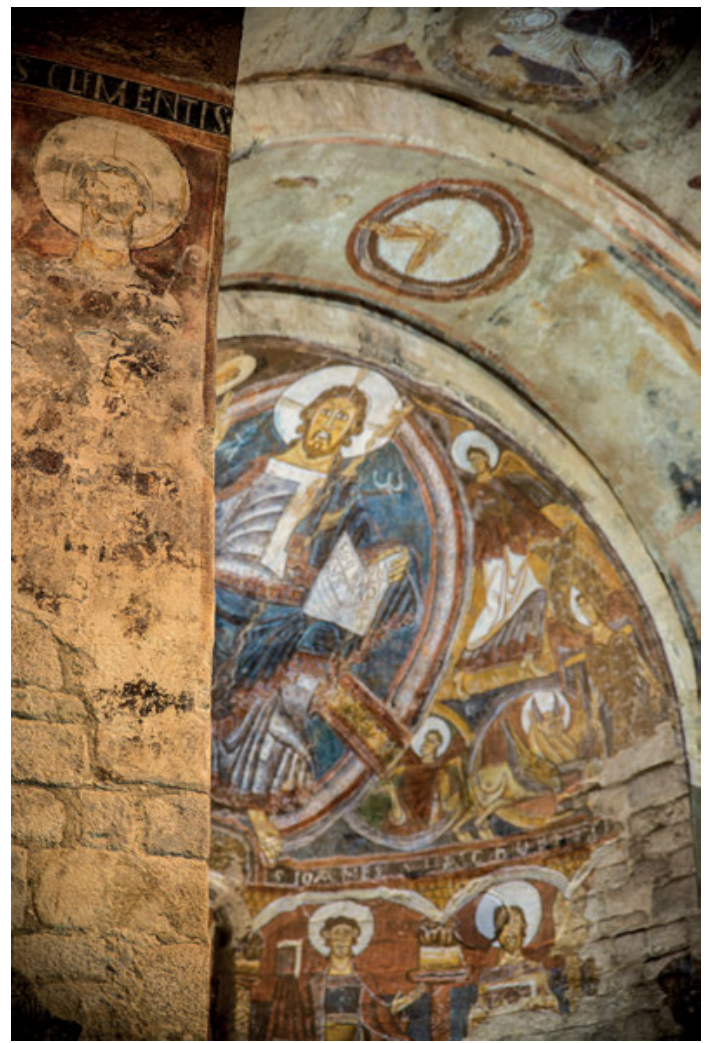

Figura 15.16: Pinturas reales y proyectadas en convivencia (Eloi Maduell/Patrimoni.gencat).

que se procesaron hasta crear un instrumento digital capaz de interpretar una partitura contemporánea pero manteniendo la tímbrica y los ambientes sonoros medievales.

El tercer estadio fue concebido como un viaje en el tiempo. Las luces de la iglesia se apagan lentamente y comienza una narración audiovisual en la cual vemos como sobre el ábside van apareciendo progresivamente las líneas que delimitan la geometría de la pintura, los fondos de color, las siluetas de las figuras y cenefas... como si fuéramos testigos de la creación del conjunto. La acción se entretiene en la Alfa y la Omega, en la inscripción Ego sum lux mundi en las pinceladas que progresivamente van creando el rostro de Cristo... Poco a poco se va construyendo todo el conjunto, que podemos contemplar solo parcialmente iluminado con lo que parece la luz de unas velas. Finalmente, la luz baña todo el ábside y contemplamos el conjunto completo (Figura 15.17). 


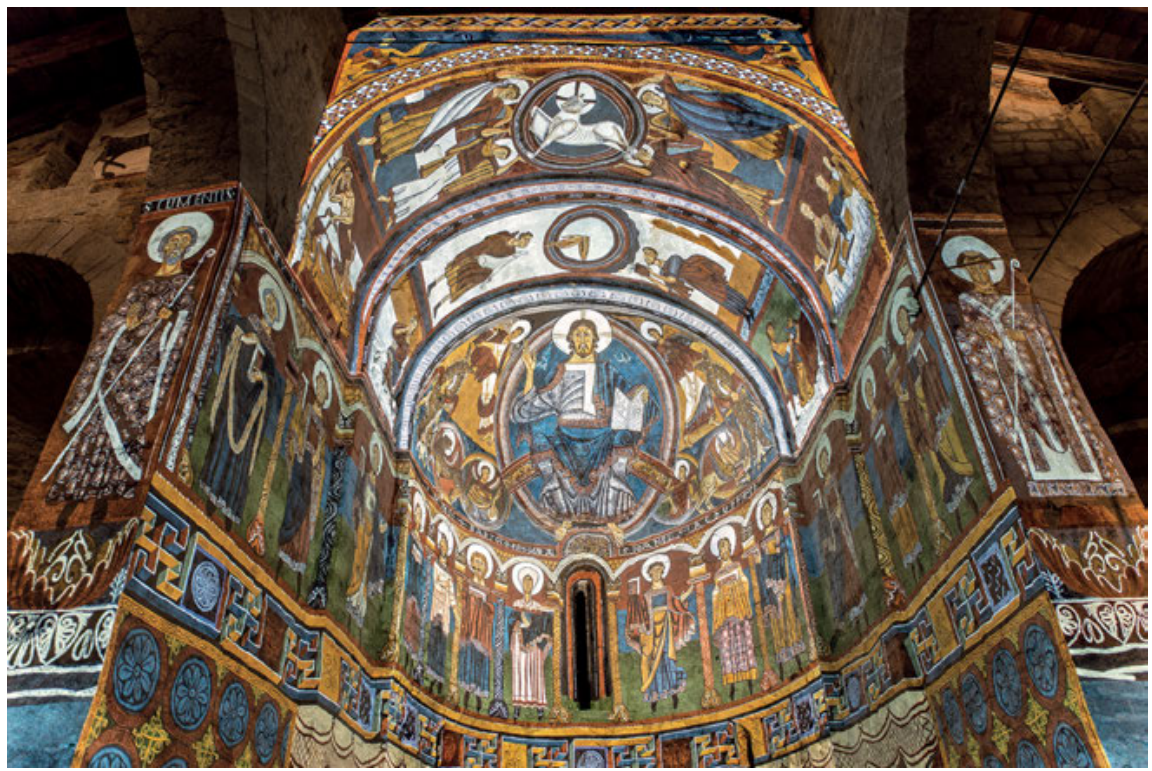

Figura 15.17: Las pinturas como debían ser en 1123 (Eloi Maduell/Patrimoni.gencat).

En un giro final, un haz de luz nos desvela lo que hay detrás de la magia y nos devuelve al tiempo presente, dejando ante nosotros los muros desnudos, con las capas profundas y las pinturas físicas como únicas compañeras.

El ciclo temporal por el cual se proyectan los tres estadios fue establecido en 30 minutos. Durante 17 se proyectan las pinturas existentes (estadio 2), posteriormente se proyecta la restitución a 1123 (estadio 3), con 9 minutos de duración y que en su final nos traslada al ábside desnudo (estadio 1) que permanece durante 3 minutos y vuelta a empezar. De esta forma, en el tiempo estimado de visita (35-45 minutos) cada visitante puede contemplar los tres, y si lo desea puede ver dos veces el fragmento audiovisual, lo que ocurre con frecuencia.

\section{Conclusión}

¿Responde de forma favorable el público a estas nuevas formas de comunicación? No disponemos de encuestas de valoración concretas para el caso de Taüll, pero los datos de asistencia, que cambian radicalmente en noviembre de 2013 cuando se pone en marcha el mapping, se pueden interpretar claramente en este sentido (Figura 15.18).

Por todo ello creemos que la creación de modelados 3D, de experiencias de realidad virtual o los mappings pueden ser una herramienta más en las manos de 


\section{VISITANTES A SANT CLIMENT DE TAÜLL}

En Noviembre de 2013 se inaugura el mapping y cambia la tendencia de pérdida de visitantes por un crecimiento sostenido

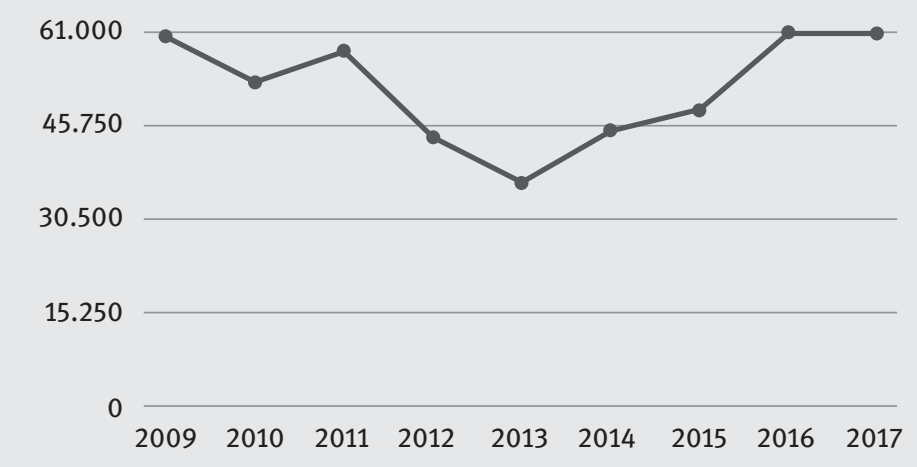

Figura 15.18: Gráfica de visitantes de Sant Climent de Taüll.

(Consorci del Patrimoni Mundial de la Vall de Boí. Informe no publicado)

los conservadores y restauradores. Utilizando siempre la investigación y el conocimiento científico como base, y buscando a través de la narrativa establecer puentes entre los significados del pasado y las percepciones del público contemporáneo, este tipo de actuaciones nos puede llevar a una nueva concepción de la experiencia cultural, completa, satisfactoria y beneficiosa tanto para el público como para la supervivencia y difusión de los valores del patrimonio.

\section{Referencias bibliográficas}

Abelló, Mariona/Sierra, Albert (2000): “El programa Vall de Boí”. En: XIII Congreso de Conservación y Restauración de Bienes Culturales. Barcelona: Generalitat de Catalunya. Bedford, Jon (2017): Photogrammetric Applications for Cultural Heritage. Guidance for Good Practice. Swindon: Historic England. [En línea, https://content.historicengland.org. uk/images-books/publications/photogrammetric-applications-for-cultural-heritage/ heag066-photogrammetric-applications-cultural-heritage.pdf/, consulta en 06/03/2018]. Boardman, Clive/Bryan, Paul (2018): 3D Laser Scanning for Heritage: Advice and Guidance on the Use of Laser Scanning in Archaeology and Architecture. Swindon: Historic England. [En línea, https://content.historicengland.org.uk/images-books/publications/3d-laserscanning-heritage/heag155-3d-laser-scanning.pdf/, consulta en 06/03/2018].

Boucher, Jean-Jacques (1990): Chambord. Paris: F. Lanore. 
Brillhart, Jessica (2016): In the Blink of a Mind. Prologue. [En línea, https://medium.com/thelanguage-of-vr/in-the-blink-of-a-mind-prologue-7864c0474a29, consulta en 06/03/2018].

Camps, Jordi/Sierra, Albert (2015): “El románico visto des del siglo XXI”. En: RDM. Revista de Museologia, 62, pp. 92-102.

Crenshaw, Matt/Obermeyer, Cheryl (2003): Targeting Museum Visitors With Email Marketing. [En línea, https://www.museumsandtheweb.com/mw2003/papers/crenshaw/crenshaw. html, consulta en 06/03/2018].

Forte, Mauricio/Pescarin, Sofia/Pujol-Tost, Laia (2006): “VR Applications, New Devices and Museums: Visitors' Feedback and Learning. A Preliminary Report”. En: Ioannides, Marinos/ Arnold, David/Niccolucci, Franco/Mania, Katerina (ed.): The 7th International Symposium on Virtual Reality, Archaeology and Cultural Heritage VAST. pp. 64-69.

Gómez, Marisa (2017): “La evolución del análisis de pinturas y policromías”. En: La Ciencia y el Arte VI. Ciencias experimentales y conservación del patrimonio. Ministerio de Educación, Cultura y Deporte, pp. 7-21.

Íbar, Elsa/Riu-Barrera, Eduard (2014): "Sant Climent de Taüll: noves estratègies de restitució i divulgació del patrimoni a la Vall de Boí.” En: XXXVIIè Curset jornades internacionals sobre la intervenció en el patrimoni arquitectònic. "Patrimoni sacre: permanent innovació" Barcelona: ADIPA. COAC. [En línea, http://upcommons.upc.edu/handle/2099/16413, consulta en 06/03/2018].

La Magnética (2014): Do Museums Worldwide form a true Community on Twitter? [En línea, http://www.lamagnetica.com/twitter-museum-study/download/museums-worldwidecommunity-twitter.pdf, consulta en 06/03/2018].

Lozano Vilardell, Francisco Javier (2011-2012): “Rèplica del Retaule de la passió, mort, resurrecció i ascensió de Crist, de Bernat Saulet (MEV 576). Escultura i noves tecnologies. Descripció del procediment tècnic”. En: Quaderns del MEV, V, pp. 243-250. [En línea, http://www.raco.cat/index.php/QuadernsMEV/article/view/264099, consulta en 06/03/2018].

Lux (1956): “Albi de pourpre vètu”. En: Lux: la revue de l'éclairage, 1, Janvier-Février-Mars, p. 89.

Lux (1956a): "Quelques nouveaux spectacles de son et lumière”. En: Lux: la revue de l'éclairage, 4, Octobre-Novembre, pp. 112-114.

Maniello, Donato (2015): Augmented reality in public spaces: Basic techniques for video mapping. Brienza: Le Penseur.

Marlowe, Elizabeth (2001): “Cold War Illuminations of the Classical Past: the Sound and Light Show on the Athenian Acropolis". En: Art History, 24.4, pp. 578-597.

Mateos, Santos M./Guifreu, Arnau (2014): "Reconstruccion y activación del patrimonio artístico con tecnologia audiovisual. Experiencia de Taüll 1123”. En: El profesional de la Información, 23.5, pp. 527-533. [En línea, http://dspace.uvic.cat:8888/ handle/10854/3276, consulta en 06/03/2018].

McGrath, Ian (1992): Son et Lumiere: an epic reading. Doctor of Creative Arts thesis. Wollongong: School of Creative Arts, University of Wollongong. [En línea, http://ro.uow. edu.au/theses/956, consulta en 27/12/2016].

Natural History Museum (2015): Explore Virtual Reality with David Attenborough's First Life. [En línea, http://www.nhm.ac.uk/discover/news/2015/june/dive-back-in-time-with-davidattenborough-s-first-life.html, consulta en 06/03/2018].

Pagès, Montserrat (2013): "Sant Climent de Taül: noves pintures, nova lectura”. En: Anuari Verdaguer, 21. [En línea, http://www.raco.cat/index.php/AnuariVerdaguer/article/ viewFile/279189/367708, consulta en 06/03/2018]. 
Pan, Diana (2015): The 360-degree view: Why an integrated CRM platform is important in growing a museum's membership program. [En línea, https://mwa2015. museumsandtheweb.com/paper/the-360-degree-view-why-an-integrated-crm-platformis-important-in-growing-a-museums-membership-program/, consulta en 06/03/2018].

Potenziani, Marco/Corsini, Massimiliano/Callieri, Marco/Di Benedetto, Marco/Ponchio, Federico/Dellepiane, Matteo/Scopigno, Roberto (2014): “An Advanced Solution For Publishing 3D Content On The Web". En: Proctor, Nancy/Cherry, Rich (eds.): Museums and the Web 2013. Silver Spring, MD: Museums and the Web. [En línea, http://mwf2014. museumsandtheweb.com/paper/an-advanced-solution-for-publishing-3d-contents-onthe-web/, consulta en 06/03/2018].

Pujol, Laia (2004): “Archaeology, museums and virtual reality”. En: Digit.HVM. Revista Digital d'Humanitats, 6, pp. 1-9. [En línea, http://www.uoc.edu/humfil/articles/eng/pujol0304/ pujol0304.pdf, consulta en 06/03/2018].

Pujol-Tost, Laia (2017): ““3D·CoD’: A New Methodology for the Design of Virtual RealityMediated Experiences in Digital Archeology”. En: Frontiers in Digital Humanities, 4.16. [En línea, https://doi.org/10.3389/fdigh.2017.00016, consulta en 06/03/2018].

Riu-Barrera, Eduard/Tarrida, Eva (2014): “La nova configuració de l'absis major de Sant Climent de taull amb els vestigis d'art fugitiu”. En: Alcoy, Rosa (ed.): Art fugitiu. Estudis d'art medieval desplaçat (EMAC-CONTEXTOS). Barcelona: Universitat de Barcelona, Publicacions i Edicions, pp. 33-52.

Sierra, Albert (2015): \#Taull1123: Immersive experience in a World Heritage Site (or augmented reality without devices). [En línea, https://mw2015.museumsandtheweb.com/paper/ taull1123-immersive-experience-in-a-world-heritage-site-or-augmented-reality-withoutdevices/, consulta en 06/03/2018].

Sierra, Albert (2016): Patrimonio cultural y tecnologia. 10 Tendencias de futuro. [En línea https://www.slideshare.net/ACdPC2016/patrimonio-cultural-y-tecnologa-10-tendenciasde-futuro-es, consulta en 06/03/2018].

Sierra, Albert (2017): “Mappings: aumentar la realidad del patrimonio. El ejemplo de \#Taüll1123". En: La Ciencia y el Arte VI. Ciencias experimentales y conservación del patrimonio. Ministerio de Educación, Cultura y Deporte, pp. 82-100.

Stein, Robert/Wayman, Bruce (2014): Seeing the Forest and the Trees: How Engagement Analytics Can Help Museums Connect to Audiences at Scale. [En línea, https://mw2014. museumsandtheweb.com/paper/seeing-the-forest-and-the-trees-how-engagementanalytics-can-help-museums-connect-to-audiences-at-scale/, consulta en 06/03/2018].

Vázquez-Moliní, Daniel/Álvarez Fernández-Balbuena, Antonio/García Botella, Ángel/Herráez, Juan Antonio/Del Egido, Marian/Ontañón, Roberto (2010): “Advanced LED lighting system applied to cultural heritage goods". En: Colour and Light in Architecture_First International Conference 2010 Proceedings. [Verona:] IUAV. pp. 341-348.

Vlahakis, Vassilios/Ioannidis, Nikolaos/Karigiannis, John/Tsotros, Manolis/Gounaris, Michael/ Stricker, Didier/Gleue, Tim/Daehne, Patrick/Almeida, Luís (2002): “Archeoguide: An Augmented Reality Guide for Archaeological Sites”. En: Computer Graphics and Art History and Archaeology, 2.5, pp 52-60.

Vote, Eileen Louis (2001): A New Methodology for Archaeological Analysis: Using Visualization and Interaction to Explore Spatial Links in Excavation Data. [En línea, https://pdfs.semanticscholar. org/0353/a45883493d80e075b7ac13d000d3c0d42738.pdf, consulta en 06/03/2018]. 